\title{
EL NUEVO MUNDO DESCUBIERTO POR CRISTÓBAL COLÓN DE LOPE DE VEGA Y LOS “MALOS ESPAÑOLES” DE AZORÍN
}

\author{
Héctor Brioso Santos
}

\begin{abstract}
The essay Retratos de algunos malos españoles y de un mal español honorario by José Martínez Ruiz, Azorín, presents the issue of Lope de Vega's point of view regarding the conquest of America in his play El Nuevo Mundo descubierto por Cristóbal Colón. Although Azorin's comments on such a topic have been frequently criticized, on the grounds of his notion of Lope's "antiespañolismo", by critics like V. De Pedro, J. Entrambasaguas and J. M. Gárate Córdoba, their critique is tinged of patriotism and lack of understanding of Azorín's fundamental irony.
\end{abstract}

El supuesto o verdadero americanismo de Lope de Vega ha sido abordado críticamente en numerosas ocasiones y desde las perspectivas más variadas que quepa imaginar, comenzando por el famoso juicio adverso de don Leandro Fernández de Moratín ${ }^{1}$ y concluyendo en la defensa implícita de sụ obra ultramarina por todos aquellos estudiosos que, desde Karl Vossler hasta la crítica presente, han acometido el análisis de sus piezas de asunto indiano: El Nuevo Mundo, El Brasil restituido, El Arauco domado y La conquista de Cortés, hoy perdida. En lo que hace a la primera obra citada, que es la que nos atañe, lo más llamativo del caso es que los críticos, enfrentados a una comedia que historia nada menos que el descubrimiento de América, se creen en el deber de juzgar si la pieza está o no a la altura de su referente histórico, la empresa americana desde $1492^{2}$.

\footnotetext{
${ }^{1}$ La llamada "comedia de las más disparatadas de Lope", le atribuye acciones "en medio del mar y en el aire" y añade que "en la tercera jornada hay una confusa mezcla de fornicación y doctrina cristiana, teología y lujuria, que no hay más que pedir", en Obras póstumas de D. Leandro Fernández de Moratín (Madrid, 1867) vol. III, 133-134.

${ }^{2}$ Aunque la cuestión no nos interese más que marginalmente, señalaremos algunos de sus hitos esenciales. La solución dada por M. Menéndez y Pelayo al problema de la mala calidad de la comedia lopesca merecería por sí misma un estudio monográfico. El polígrafo montañés sustenta, en general, la hipótesis de que la conquista no produjo una literatura acorde con su importancia historica por superar la historia a los cauces literarios: "la realidad histórica excede aquí a toda ficción" [Antología de poetas hispanoamericanos (Madrid, 1893-1895) vol. I, 38; aunque su análisis pormenorizado de la comedia aparece en sus Estudios sobre el teatro de Lope de Vega, E. Sánchez Reyes, ed. (Santander, 1949) vol. V, 306-325]. Después de don Marcelino, la polémica en torno a esta comedia ha continuado: vid. K. Vossler, Lope de Vega y su tiempo, trad. de R. de la Serna (Madrid, 1933) 318319; la obra citada de Miró Quesada, 24-32; la conocidísima de M. A. Morínigo, América en el teatro de Lope de Vega, [Buenos Aires, 1946 (anexo II de la Revista de Filología Hispánica)] 221-227; y J. de Entrambasaguas, en el prólogo a su adaptación teatral de El Nuevo Mundo... (Madrid, 1963) xxi-xxii. Modernamente, vid. también,
} 
Pero uno de los acechos que suscitan el mayor grado de sorpresa y desconcierto en el lector de este siglo sigue siendo el Lope americanista de la galería de "Retratos de algunos malos españoles y de un mal español honorario" de Azorín ${ }^{3}$, ya que la lectura que hace Martínez Ruiz del punto de vista lopiano es tan ambigua que ha suscitado algunas interpretaciones erróneas de la crítica posterior.

En efecto, en sus "Retratos", firmados en el pueblo castellano imaginario de Nebreda en marzo de 1912 (656), aparece un pasaje titulado "Lope de Vega" (645-648), en el que se leen frases como las siguientes:

¿Por qué es un mal español Lope? ¿Por qué tiene, principalmente, un puesto en esta galería? Por su comedia El Nuevo Mundo descubierto por Colón. En esa obra está condensado cuanto se ha estado pensando durante mucho tiempo de nuestra conducta en América.

Para citar, a continuación, un texto de la comedia lopesca en el que su autor pone en boca de un carácter indígena, que representa escénicamente al demonio, una queja contra la vertiente materialista de la empresa:

$$
\begin{aligned}
& \text { Estos, codiciando el oro } \\
& \text { de los indios, se hacen santos, } \\
& \text { fingen cristiano decoro, } \\
& \text { mientras vienen otros tantos } \\
& \text { que llevan todo el tesoro } \\
& \text {... } \\
& \text { Con falsa religión y falsos dioses, } \\
& \text { nos venís a robar oro y mujeres }{ }^{4} \text {. }
\end{aligned}
$$

Y sigue Martínez Ruiz con su demostración elusiva de la culpabilidad del Fénix:

Un consenso universal ha condenado nuestra conquista americana. Lope marcha en compañia, entre nosotros, de Voltaire, Montaigne, Herder, Andrés Chénier... No tenemos -todos, al menos- de cuantos vivimos en estos tiempos ningún pacto celebrado con las gentes de los siglos XV y XVI. No necesitamos, como ahora se hace, que se nos excuse por lo que en aquellas centurias hicimos... Hombres habrá siempre que condenen la iniquidad y que crean que el haberla cometido ciudadanos antecesores suyos, tres siglos atrás, no es para ellos ningún baldón. El baldón consistiría -puerilmente- en querer paliar lo que no tiene paliativo (647-648).

Que es, en realidad, una indirecta defensa de Lope de Vega, con el reconocimiento de la justeza de su planteamiento histórico, a la par que el intento de asentar una opinión histórica ponderada acerca del viejísimo combate de las leyendas negra y blanca entre sí.

entre otros, de J. Lemartinel y Ch. Minguet, la introducción a su edición de El Nuevo Mundo descubierto por Cristóbal Colón (Lille, 1980); R. L. Shannon, Visions of the New World in the Plays of Lope de Vega (New York, 1989); y J. H. Parker, "Releyendo El nuevo mundo descubierto por Cristóbal Colón de Lope de Vega" en K. H. Körner y Georg Zimmermann, eds., Homenaje a Hans Flasche. Festschrift zum 80. Geburstag (Stuttgart, 1991) 357-363.

${ }^{3}$ En adelante, las citas procederán de sus Obras completas, A. Cruz Rueda, ed. (Madrid, 1947) vol. II, 643-656.

${ }^{4}$ Son los versos 2741 y ss. del acto III de la edición crítica de Lemartinel y Minguet. 
Tan equívoco resulta, sin embargo, el tono azoriniano que un estudioso como Valentín de Pedro ha acometido la defensa del Fénix frente a los embates de Martínez Ruiz. Señala que el juicio sumario de Azorín se debía a ignorancia y a "parcialidad enemiga":

No ocultar lo que de reprobable tuvo la conquista no es lo mismo que condenarla alegando lo que tuvo de reprobable. Lo primero enaltece a quienes lo hicieron, lo segundo es prueba manifiesta de parcialidad enemiga ${ }^{5}$.

Aunque, a lo largo de su análisis, reconoce que la crítica de Azorín al Fénix no es tan simple, como cuando indica que el título "Retratos de algunos malos españoles" "entraña una réplica irónica a quienes no conciben un patriotismo con los ojos abiertos a los defectos de su patria o de sus compatriotas" (91). Lo que, en realidad, parece haber ofendido más a De Pedro es la lista azoriniana citada de portavoces de la "leyenda negra", en la que Lope aparece flanqueado nada menos que por grandes enemigos tradicionales de España, los extranjeros Voltaire, Montaigne, Herder o André de Chenier. Entonces replica al alicantino:

Pero hay una diferencia, una gran diferencia, entre Lope y aquellos que Azorín le da por compañeros, a nuestro juicio indebidamente, pues lo que en Lope es parte de un todo, en los otros es el todo, lo que cambia el aspecto de la cuestión de modo fundamental. Teniendo, además, a su favor, Lope, el ser poeta de la nación conquistadora, lo que supone una libertad de opinión y una independencia de juicio que se ven pocas veces en casos semejantes (92).

Si, en lo esencial, De Pedro glosa acertadamente la crítica de Azorín, en el espíritu de la letra sus notas desenfocan la cuestión al reducirla a una sola frase, exagerada, del noventayochista, y pretenden revolver contra éste argumentaciones más extremas que las que él mismo aventuraba en sus "Retratos". La crítica de De Pedro adopta, además, un tinte nacionalista y conservador que el ensayo original no poseía o que disimulaba pudorosamente, algo muy llamativo para la época y la generación de su autor, nacido en 1873.

En 1963 y 1977, respectivamente, con menos comprensión que De Pedro y un punto más de oportunismo crítico, Joaquín de Entrambasaguas y José M. Gárate Córdoba se limitan a reproducir con entusiasmo sus comentarios sin señalar o atenuar ninguna de sus manifiestas exageraciones. Más bien, las extremarán un poco más, al acusar a Azorín de crasa ignorancia. Entrambasaguas, a un propio tiempo, elogia a De Pedro y ataca a Azorín con verdadera acritud:

[Es] tan penetrante como noble su actitud española [se refiere a De Pedro] de condenar, por ignorantes, unas palabras de Azorín en sus Lecturas españolas, a veces no poco tartamudas como en este caso. El párrafo [de De Pedro], por su sobrio razonamiento frente al extranjerismo harto pedante del inventor de la 'generación del 98', pro domo sua merece reproducirse....

A su vez, Gárate Córdoba también aducirá la ignorancia y la superficialidad del escritor del 98 y atacará el sentimiento que llama, de un modo revelador, "la cerrazón antiespañola de nuestros detractores"?.

\footnotetext{
${ }^{5}$ América en las letras españolas del Siglo de Oro (Buenos Aires, 1954) 92.

${ }^{6}$ Obra citada, $x x$.

${ }^{7}$ La poesía del descubrimiento (Madrid, 1977) 73-74.
} 
En los años ochenta, a semejantes críticas han sucedido opiniones más matizadas, sobre la comedia lopesca y sobre las consideraciones de Azorín, como la de Patrizia Garelli. Esta estudiosa escribe que las "quejas apasionadas" contra los colonos peninsulares que contiene El Nuevo Mundo

...ya hicieron caer en error a Azorín, dado que incluye a Lope entre sus 'malos españoles'... Si pudieran inducirnos muchas afirmaciones, desvinculadas de su contexto, al error de considerar a Lope como un anticolonialista convencido, la fórmula de fondo de las dos comedias [El Nuevo Mundo y el Arauco domado], constituye claro testimonio de que el pensamiento del autor no presenta vacilación alguna acerca de la licitud de la empresa española en el Nuevo Mundos.

En 1993, Francisco Ruiz Ramón anota, en su Introducción a la edición antológica titulada América en el teatro clásico español, otro comentario acertado, aunque breve, a nuestro pasaje de Azorín, sin omitir una alusión crítica a sus predecesores:

Azorín, en sus Lecturas españolas, con cáustica ironía -que tantos críticos no han sabido encajar, al entenderla literalmente- situaba a Lope, por esta obra, entre los "malos españoles", junto a Fray Luis de León, Cervantes y Larra?.

Así pues, en justicia, a nuestro modo de ver, Azorín no parece haber pretendido acusar a Lope de verdadera traición a España o, en todo caso, de ese mismo pecado que, especiosamente, atribuye a Fray Luis, a Cervantes, a Gracián, a Moratín, a Larra y a Gautier, el "mal español honorario" del título. Precisamente, el hecho de que aparezca el Fénix rodeado de figuras que merecían inmenso respeto intelectual al escritor de Monóvar debería haber sido una pista cabal de interpretación para estos críticos tan españolistas. Lo que impulsa a nuestro escritor es, más bien, el mismo deseo de reivindicar la integridad intelectual y la necesidad de conocer la veracidad histórica, entre otras verdades, que observa en Lope y que, evidentemente, también contempla en Cervantes y los demás. Según declara en la porción final de los "Retratos", titulada "Epílogo en Castilla":

Esos españoles eminentes que hemos hecho desfilar por estas páginas movidos estaban de una insaciable curiosidad intelectual... No saldrá España de su marasmo secular mientras no haya millares y millares de hombres ávidos de conocer y comprender (656).

La crítica a Azorín, así pues, parece responder, como tantas veces, a una grave pérdida. de perspectiva, que en este caso cabe calificar de total incompresión del contexto azoriniano, de la intención implícita, y al final, bien implícita, de su catálogo de beneméritos "malos españoles".

De una sola cosa podría acusarse entonces al noventayochista, y es precisamente de haber descontextualizado la cita ya mencionada de Lope de su página 647, que principia "Estos, codiciando el oro..." y termina "nos venís a robar oro y mujeres"10. Estas palabras

\footnotetext{
8 "Lope de Vega y la conquista de América: teatro y opinión pública", en Actas del Coloquio: Teoría y realidad en el teatro español del siglo XVII. La influencia italiana (Roma 16 a 19 de noviembre de 1978) (Roma, 1981) 289-296; cita en 292.

${ }^{9}$ [Pamplona, 1993 (números anejos de RILCE, n 12)] 43.

${ }^{10}$ De hecho, es de notar que esta famosa cita de siete versos de El Nuevo Mundo sobre la que Azorín cifraba su ensayito de los "malos españoles" se va acortando progresivamente en sus detractores: si De
} 
polémicas, paradójicamente, -esto hay que anotarlo en favor de Lope y en detrimento de Martínez Ruiz- aparecían, según se ha dicho, en la comedia en boca del demonio, una circunstancia que, evidentemente, debía influir muy decisivamente en su recta interpretación por el público del corral y que, al día de hoy, es olvidada sospechosamente por un gran sector de la crítica especializada a la hora de elegir sus citas.

No es imposible, por otra parte, que la expresión azoriniana que nos ocupa proceda en lo formal de la misma acusación que hace Quevedo contra los "malos españoles" que hacen "cosas execrables" en Indias, en su "Lince de Italia u zahorí español"11, algo esperable en un gran lector de los clásicos como era Martínez Ruiz y especialmente cuando el famoso pasaje quevedesco es una de las fuentes de obligada consulta para cualquier interesado por la imagen de América en los autores áureos.

Azorín, como miembro de la Generación del 98, vivió la gran época de las conmemoraciones en torno al cuarto centenario del descubrimiento, conoció el renacimiento de las viejas polémicas de la leyenda negra hacia 1914, fecha del libro de Julián Juderías ${ }^{12}$, y, finalmente, tras el alzamiento franquista, la etapa de nacionalcatolicismo que dio origen a estudios apologéticos del españolismo lopiano como los de Vicente Rodríguez Casado ${ }^{13}$ o Constancio Eguía Ruiz ${ }^{14}$. Pese a semejantes injerencias, el buen juicio de Martínez Ruiz le permitió, sin duda, mantener su independencia de criterio frente a la marea conservadora y sustentar tesis tan actuales y tan audaces como las formuladas en "Algunos retratos...". En fin, puede concluirse esta nota con la misma frase que Vossler dedicó en su obra citada al Lope de El Nuevo Mundo, ahora aplicable a los "Retratos" de Azorín mismo: "No sería cuestión de si la obra está anticuada o no, sino de si hay la madurez y el discernimiento necesarios por nuestra parte..." (319).

Pedro la citaba y glosaba ampliamente sin omitir ningún verso, Entrambasaguas la reducirá a solo dos versos como el modo más fácil de descartar el juicio del noventayochista. Evidentemente, si en el texto azoriniano el manejo de la fuente lopesca era criticable, más lo será en los que lo critican sin documentar cuidadosamente sus asertos.

${ }^{11}$ Obras completas. Prosa, F. Buendía, ed. (Madrid, 1986) vol. I, 885.

${ }^{12} \mathrm{La}$ leyenda negra. Estudios acerca del concepto de España en el extranjero (Barcelona, 1914).

13 "Lope de Vega en Indias", Escorial, 34 (1943) 249-264.

14 "El Fénix de los Ingenios, genio de la raza", Boletín de la Real Academia Española, 22 (1935) 569-647. 